\title{
Transformation of soil texture schemes and determination of water-physical properties of soils Alexander Sadovski ${ }^{a},{ }^{*}$, Mariya Ivanova ${ }^{b}$
}

a Bulgarian Science Center of the IEAS, Sofia, Bulgaria b Institute of Soil Science, Agrotechnologies and Plant Protection, Sofia, Bulgaria

Article Info

Received : 28.02 .2020

Accepted : 19.06 .2020

\begin{abstract}
Measuring soil water-physical properties is laborious, time-consuming, and expensive. That provokes a lot of scientists to estimate them which action is troubled by the usage of different soil texture classification systems. The study proposes a rapid, reliable, and universally applicable methodology for soil textural transformations between different classification systems. The method of discrete mathematics is applied to make the conversion of particlesize classes from the Kachinsky system, which is used in Bulgaria to the International systems. Three different data sources were used to determine the water-physical properties of soils from textural data - 376 soil profiles from Bulgaria, extraction from the SoilGrids system for the Plovdiv district in Bulgaria and data from CanSIS/NSDB database. The relationship between the dependent variables field capacity (FC), wilting point (WP) and bulk density (BD), and independent variables sand, silt, and clay soil content was sought in the form of a regression equation. The applied stepwise regression procedure produces a close dependence between the soil texture and its water-physical properties.
\end{abstract}

Keywords: Bulk density, discrete mathematics, field capacity, soil texture, wilting point.

(C) 2020 Federation of Eurasian Soil Science Societies. All rights reserved

\section{Introduction}

In the near past, the Bulgarian experience in applying methods tried to unify the most used soil texture schemes and to find equations for estimating soil properties from soil texture data. Kolev et al. (1996) determined a regression model to convert from a texture-based soil classification system used in Bulgaria to the classification system described in Van Keulen and Wolf (1986). They show also that soil moisture content at complete saturation, field capacity and wilting point can be predicted from soil texture data using the exponential approach suggested by Van Keulen. Another study determines the coefficients in the regression dependencies between the measured W33 and W1500 (in \% by mass) - these are field capacity (FC) and wilting point (WP), and the content of clay (Cl) and organic carbon (OC) from the horizons of the 4 profiles (Dimitrov and Kercheva, 2016).

Rousseva (1997) defined closed-form models of exponential and power-law for data transformations between the three worldwide used soil texture schemes: Kachinsky's (Kachinsky, 1956), the International system suggested by Robinson (1927) and approved by the Second International Congress of Soil Science in Leningrad (Sokolovsky and Kachinsky, 1930), and USDA (Soil Survey Staff, 2017). The author defines that exponential function describes better fine-textured soils, while closed-form power functions recreate better coarse-textured soils. The defined functions represent cumulative particle-size distribution curves.

Nowadays we need a rapid, reliable, and universally applicable methodology for soil textural transformations between different classification systems and for determining the water-physical properties of soils from textural data. It was suggested that it would seem wise for most countries to consider adopting

\footnotetext{
* Alexander Sadovski Mariya Ivanova

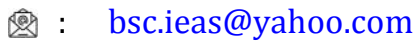

응 mulykostova@abv.bg

0000-0001-7576-4214

0000-0003-4113-8340

(Corresponding author)
} 
the particle-size limits and texture classes of the USDA/FAO system (Minasny and McBratney, 2001). They presented empirical equations to convert between the two systems.

Measuring soil water-physical properties is laborious, time-consuming, and expensive. That is why many scientists (Van Genuchten, 1980; Van Genuchten and Nielsen, 1985; Van Keulen and Wolf, 1986) try to define a way to predict them. The prediction of soil water-physical properties is also embarrassed by the usage of different soil texture classification systems.

Vereecken et al. (1989) already established relations for estimating the parameters of a modified Van Genuchten equation from basic soil properties based on 182 measured moisture retention characteristics (MRC). Using nonlinear regression the authors evaluated the link between soil data as bulk density, carbon content, and particle size distribution and the estimated values of the four Van Genuchten equation parameters for a wide range of textures. They defined that the parameters of the modified Van Genuchten equation, describing MRC, can be estimated as a function of those three soil properties with reliable accuracy.

An equation for water conductivity was derived depending on sand and clay content (in \%), and the moisture content using 230 data points (Saxton et al., 1986). Several equations for soil water characteristic estimates are given in (Saxton and Rawls, 2006). Some of them are moisture regressions with independent variables sand, clay, and organic matter. Forty-eight pedotransfer equations of the bulk density depending on the sand, silt, clay, and organic matter have been evaluated (Abdelbaki, 2018). Børgesen et al. (2008) found that introducing measured water content as a predictor generally gave lower errors for water retention predictions. Manrique et al. (1991) show that available water capacity was not related to the organic carbon content in almost all types of soils. Some research shows that cation exchange capacity was a more important factor for estimating field capacity and wilting point than clay and organic matter content (Nourbakhs et al., 2004). Soil bulk density is mainly related to the soil carbon content (Rodríguez-Lado et al., 2015).

A review of research (Fredlund et al., 1997) showed two approaches in the prediction of the soil-water characteristic curve (SWCC) from grain-size. The first approach uses a statistical estimation of properties describing the SWCC from grain-size and volume-mass properties (Ahuja et al., 1985). The second approach was theoretical and involved converting the grain-size distribution to a pore-size distribution which was then developed into an SWCC (Arya and Paris, 1981). Shein et al. (2014) made a comparative evaluation of different methods of obtaining hydrophysical information for accurate predictive modeling to forecast water movement in soils. But all the results are given only for one type of soil. The book of Pachepsky and Rawls (2004) provides the unique compendium of pedotransfer functions and shows how the value of soil data can be increased by using them in pedotransfer functions to predict soil hydrologic and related properties.

A major drawback of several results is that they determine the water-physical properties depending on thetexture only for particular soil types. In the United States, twelve major soil texture classifications are defined by the United States Department of Agriculture (Soil Survey Staff, 2017), (Figure 1).

We offer a generalized approach that relates these properties to all soil types and soil profile horizons.

A new Bulgarian transformation methodology of soil textural classification from Bulgarian (adopted Kachinsky's) to the ISSS and the USDA systems is suggested. And more important we propose a method for determining the water-physical properties of soils (field capacity, wilting point, and soil bulk density), based on data on the particle-size distributions of the soil on which the crops are grown.

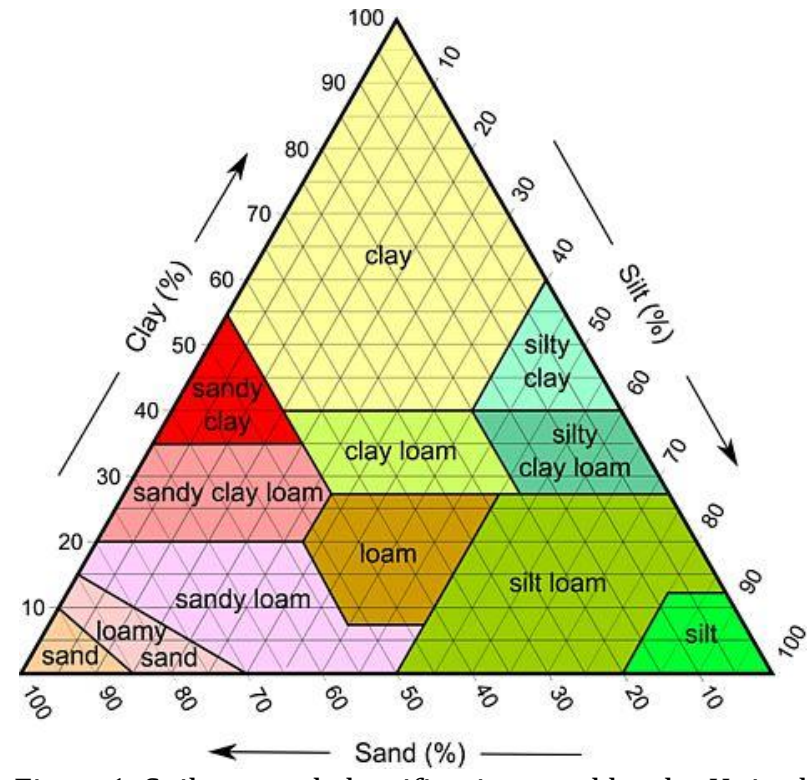

Figure1. Soil textural classification used by the United States Department of Agriculture 


\section{Material and Methods}

Particle-size classes (mm) when determining soil texture in Bulgaria follow the system of Kachinsky (Kachinsky, 1943; 1965; Antipov Karatev, 1960):

$$
\text { (<0.001); (0.001-0.005); (0.005-0.01); (0.01-0.05); (0.05-0.25); (0.25-1.0); (>1.0). }
$$

In the description of soil profiles we found the next (Figure 2$)$ :

\begin{tabular}{|c|c|c|c|c|c|}
\hline $\begin{array}{l}\text { Effective diameter } \\
\text { mechanical elements }\end{array}$ & \multicolumn{2}{|c|}{$\begin{array}{c}\text { Kachinsky } \\
\text { Classification } 1937\end{array}$} & \multicolumn{3}{|c|}{ Bulgarian Classification } \\
\hline$>3$ & Stone & & $>3$ & Stones & \\
\hline $2-3$ & Grave & & \multirow{2}{*}{$1-3$} & \multirow{2}{*}{\multicolumn{2}{|c|}{ Gravel }} \\
\hline $1-2$ & \multirow{2}{*}{ Sand } & \multirow{2}{*}{$\begin{array}{l}\text { large } \\
\text { medium } \\
\text { small }\end{array}$} & & & \\
\hline $\begin{array}{l}0.5-1.0 \\
0.25-0.5 \\
0.05-0.25\end{array}$ & & & $\begin{array}{c}0.5-1.0 \\
0.25-0.5 \\
0.05-0.25\end{array}$ & Sand & $\begin{array}{l}\text { large } \\
\text { medium } \\
\text { small }\end{array}$ \\
\hline \multirow{2}{*}{$\begin{array}{l}0.01-0.05 \\
0.005-0.01 \\
0.002-0.005 \\
0.001-0.002 \\
0.0005-0.001 \\
0.0001-0.0005 \\
<0.0001\end{array}$} & Silt & $\begin{array}{l}\text { large } \\
\text { medium } \\
\text { small }\end{array}$ & $\begin{array}{c}0.01-0.05 \\
0.005-0.01 \\
0.001-0.005 \\
\end{array}$ & Silt (dust) & $\begin{array}{l}\text { large } \\
\text { medium } \\
\text { small }\end{array}$ \\
\hline & Clay & $\begin{array}{l}\text { rough } \\
\text { thin } \\
\text { coloids }\end{array}$ & $<0.001$ & \multicolumn{2}{|l|}{ Clay } \\
\hline $\begin{array}{l}>0.01 \\
<0.01\end{array}$ & \multicolumn{2}{|c|}{$\begin{array}{l}\text { Physical sand } \\
\text { Physical clay }\end{array}$} & $\begin{array}{l}>0.01 \\
<0.01\end{array}$ & \multicolumn{2}{|c|}{$\begin{array}{l}\text { Physical sand } \\
\text { Physical clay }\end{array}$} \\
\hline
\end{tabular}

Figure 2. Comparison of Kachinsky 1937 classification and Bulgarian (adopted Kachinsky's) classification of particle size classes.

It is not compatible with the International and USDA systems for determination of Clay, Silt and Sand content in the soil. As noted, in the classification of Kachinsky, except these three classes, are adopted and more fractional divisions within individual fractions. The exact physical justification for such a more fractional division of Kachinsky in his writings does not give. This is the first serious moment to discuss the possibilities of transition from one classification to another (Shein, 2009). It is the reason for application by us the apparatus of discrete mathematics in the following way.

We now define a set (Rosen, 2012).

Definition 1. A set is an unordered collection of objects, called elements or members of the set.

A real interval $x$ is a nonempty set of real numbers

$$
\mathrm{A}=[\mathrm{a}, \mathrm{b}]=\{\mathrm{x} \mid \mathrm{a} \leq \mathrm{x} \leq \mathrm{b}\}
$$

where $a$ is called the infimum and $b$ is called the supremum.

Definition 2. Let $A$ and $B$ be sets. The intersection of the sets $A$ and $B$, denoted by $A \cap B$ is the set containing those elements in both A and B.

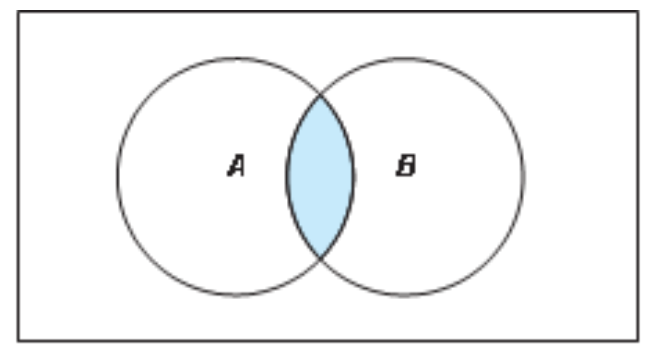

Figure 3. Venn diagram of the intersection of $A$ and $B$. $A \cap B$ is shaded.

The Venn diagram shown in Figure 3 represents the intersection of two sets $A$ and $B$. The shaded area that is within both the circles representing the sets $\mathrm{A}$ and $\mathrm{B}$ is the area that represents the intersection of $\mathrm{A}$ and $\mathrm{B}$. The intersection obeys to the next laws: 
Commutative law

$\mathrm{A} \cap \mathrm{B}=\mathrm{B} \cap \mathrm{A}$

Associative law

$A \cap(B \cap C)=(A \cap B) \cap C$

We apply these results from discrete mathematics to make the conversion of particle-size classes from the Kachinsky system, which is used in Bulgaria to the International system.

$$
\begin{aligned}
\text { Let } A & =[a 1, b 1] \text { and } B=[a 2, b 2], \\
\text { then } \quad A \cap B & =[\max (a 1, a 2), \min (b 1, b 2)]
\end{aligned}
$$

The measurement of soil bulk density is expensive and time-consuming, thus it is a parameter often excluded from ordinary soil analyses. Pedotransfer functions have been proposed as an alternate solution to determine soil bulk density from soil texture and soil organic matter content (Rodríguez-Lado, 2015). In our study data from 376 determinations of soil texture (measured in \% by Kachinsky's method) and waterphysical properties - field capacity in mm (FC), wilting point in mm (WP) and bulk density in g.cm $^{-3}$ (BD) from different profiles of Bulgarian soils were the objects of our analysis (Teoharov et al., 2009; Dilkova, 2014). As determinations of soil organic carbon (SOC) content were not available for many of these profiles, SOC is not included in our analysis. Below are the statistical properties of variables in the analysis (Table 1).

Table 1. Descriptive Statistics (Bulgarian Soils)

\begin{tabular}{lcrrrrrrr}
\hline Variable & Valid N & Mean & Median & Minimum & Maximum & \multicolumn{1}{c}{ Std.Dev. } & \multicolumn{1}{l}{ Skewness } & Kurtosis \\
\hline FC & 345 & 57.24 & 46.00 & 5.00 & 216.00 & 36.4796 & 1.6174 & 2.8769 \\
WP & 297 & 14.90 & 14.07 & 2.80 & 41.80 & 6.9901 & 0.7247 & 0.5365 \\
BD & 345 & 1.40 & 1.41 & 0.97 & 1.85 & 0.1612 & -0.1664 & -0.1918 \\
Sand & 376 & 42.14 & 40.15 & 16.78 & 82.68 & 14.0166 & 0.5751 & -0.3241 \\
Silt & 376 & 20.47 & 20.20 & 7.70 & 46.53 & 5.6575 & 0.5196 & 0.8475 \\
Clay & 376 & 33.64 & 33.24 & 4.93 & 61.05 & 14.2417 & 0.0396 & -1.0987 \\
\hline
\end{tabular}

To reduce the gap between soil data demand and availability, ISRIC (International Soil Reference Information Centre) released a Global Soil Information system called "SoilGrids" (Hengl et al., 2017). The most recent and improved version of the SoilGrids system at $250 \mathrm{~m}$ resolution provides global predictions for standard numeric soil properties (organic carbon, bulk density, cation exchange capacity, $\mathrm{pH}$, soil texture fractions, and coarse fragments, soil water content at $33 \mathrm{kPa}$ and soil water content at $1500 \mathrm{kPa}$ ). We made extraction from data file at $10 \mathrm{~cm}$ soil depth for the Plovdiv district in Bulgaria containing predicted values of the same variables. Here are their statistical properties (Table 2).

Table 2. Descriptive Statistics (Plovdiv district)

\begin{tabular}{lrrrrrrrr}
\hline \multicolumn{1}{c}{ Variable } & Valid N & \multicolumn{1}{c}{ Mean } & Median & Minimum & Maximum & Std.Dev. & Skewness & Kurtosis \\
\hline FC & 264311 & 33.06 & 33.00 & 23.00 & 47.00 & 1.9223 & -0.0157 & -0.6275 \\
WP & 264311 & 15.25 & 16.00 & 7.00 & 25.00 & 2.1421 & 0.3926 & 0.0622 \\
BD & 264311 & 1.29 & 1.35 & 0.61 & 1.66 & 0.1774 & 0.6884 & 0.6965 \\
Sand & 264311 & 36.08 & 36.00 & 12.00 & 58.00 & 6.8423 & 0.1713 & 0.5595 \\
Silt & 264311 & 40.26 & 40.00 & 22.00 & 52.00 & 2.8555 & -0.0468 & -0.4911 \\
Clay & 264311 & 23.66 & 24.00 & 8.00 & 48.00 & 5.0258 & -0.0711 & -0.3980 \\
\hline
\end{tabular}

It is evident that a very large number of point data are available for our analysis.

To make comparisons with data from another country we select data from CanSIS/NSDB database, which is explained in the Manual (MacDonald and Valentine, 1992). Below are their statistical properties (Table 3).

Table 3. Descriptive Statistics (Canadian Soils)

\begin{tabular}{lrrrrrrrr}
\hline \multicolumn{1}{c}{ Variable } & \multicolumn{1}{c}{ Valid N } & \multicolumn{1}{c}{ Mean } & \multicolumn{1}{c}{ Median } & Minimum & Maximum & \multicolumn{1}{c}{ Std.Dev. } & \multicolumn{1}{c}{ Skewness } & \multicolumn{1}{c}{ Kurtosis } \\
\hline FC & 54274 & 27.03 & 28.00 & 0.00 & 70.00 & 11.6470 & -0.0553 & -0.8312 \\
WP & 54274 & 14.23 & 14.00 & 0.00 & 50.00 & 7.7475 & 0.3695 & -0.5024 \\
BD & 54274 & 1.41 & 1.40 & 0.10 & 2.13 & 0.1812 & -0.0137 & 2.1839 \\
Sand & 54274 & 44.92 & 43.00 & 0.00 & 100.00 & 26.6372 & 0.1936 & -1.0346 \\
Silt & 54274 & 33.30 & 34.00 & 0.00 & 94.00 & 16.7135 & 0.1172 & -0.3662 \\
Clay & 54274 & 21.78 & 18.00 & 0.00 & 96.00 & 16.2006 & 1.1272 & 1.1713 \\
\hline
\end{tabular}

Having such a large amount of data on soil texture and water-physical properties is a prerequisite for drawing reliable conclusions about the relationships between them. 


\section{Results and Discussion}

Bulgarian intervals follow Kachinsky's system and they do not correspond to USDA and ISSS classes. We are considering the ISSS intervals before FAO (2006) guidelines. Two of the intervals $(0.001-0.005)$ and $(0.01$ 0.05 ) should be split into parts to conform to the ISSS system.

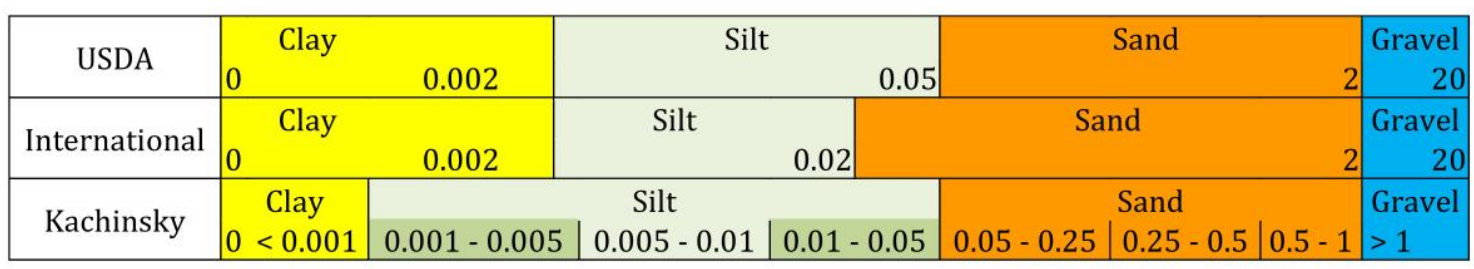

Figure 4. Relationships particle-size ( $\mathrm{mm}$ ) of the USDA, ISSS, and Kachinsky systems.

Applying the exposed method from discrete mathematics is obtained with MATLAB code:
$\mathrm{K} 1=[0.001,0.002,0.003,0.004,0.005]$
$\mathrm{I} 1=[0.001,0.002]$
Kachinsky interval (0.001-0.005)
Clay = intersect $(\mathrm{K} 1, \mathrm{I} 1)$;
ISSS interval $(0.001-0.002)$
$=(0.001,0.002)$, (Figure 5)

Analogous

$$
\begin{array}{ll}
\mathrm{K} 2=[0.01,0.02,0.03,0.04,0.05] ; & \text { Kachinsky interval }(0.01-0.05) \\
\mathrm{I} 2=[0.01,0.02] ; & \text { ISSS interval }(0.01-0.02) \\
\text { Silt = intersect }(\mathrm{K} 2, \mathrm{I} 2) ; & =(0.01,0.02),(\text { Figure } 6)
\end{array}
$$

\begin{tabular}{|c|c|ccc|}
\cline { 2 - 5 } \multicolumn{1}{c|}{} & Clay & \multicolumn{3}{c|}{ Silt } \\
\hline & \multicolumn{2}{|c|}{} & \multicolumn{3}{c|}{} & | & \\
\hline 0.001 & 0.002 & 0.003 & 0.004 & 0.005 \\
\hline
\end{tabular}

Figure 5. Splitting interval K1 in proportion 1:3.

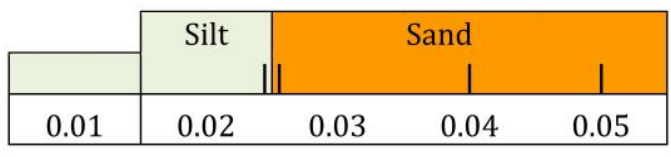

Figure 6. Splitting interval K2 in proportion 1:3.

Here we have formulas for conversion from Bulgarian (adopted Kachinsky's) to the ISSS system, which are used in our analysis:

Clay $=(<0.001)+1 / 4(0.001-0.005)$;

Silt $=3 / 4(0.001-0.005)+(0.005-0.01)+1 / 4(0.01-0.05)$;

Sand $=3 / 4(0.01-0.05)+(0.05-0.25)+(0.25-1.0)+(>1.0)$

Gravel $=100-(<0.001)+(0.001-0.005)+(0.005-0.01)+(0.01-0.05)+(0.05-0.25)+(0.25-1.0)+(>1.0)$.

Interpolation of the intervals is linear, which gives easier and better approximation than results derived according to the logarithmic scale.

Bulgarian intervals also do not correspond to the USDA and classes. The interval (0.001 - 0.005) should be split into parts to conform to the USDA system. The corresponding MATLAB code is:

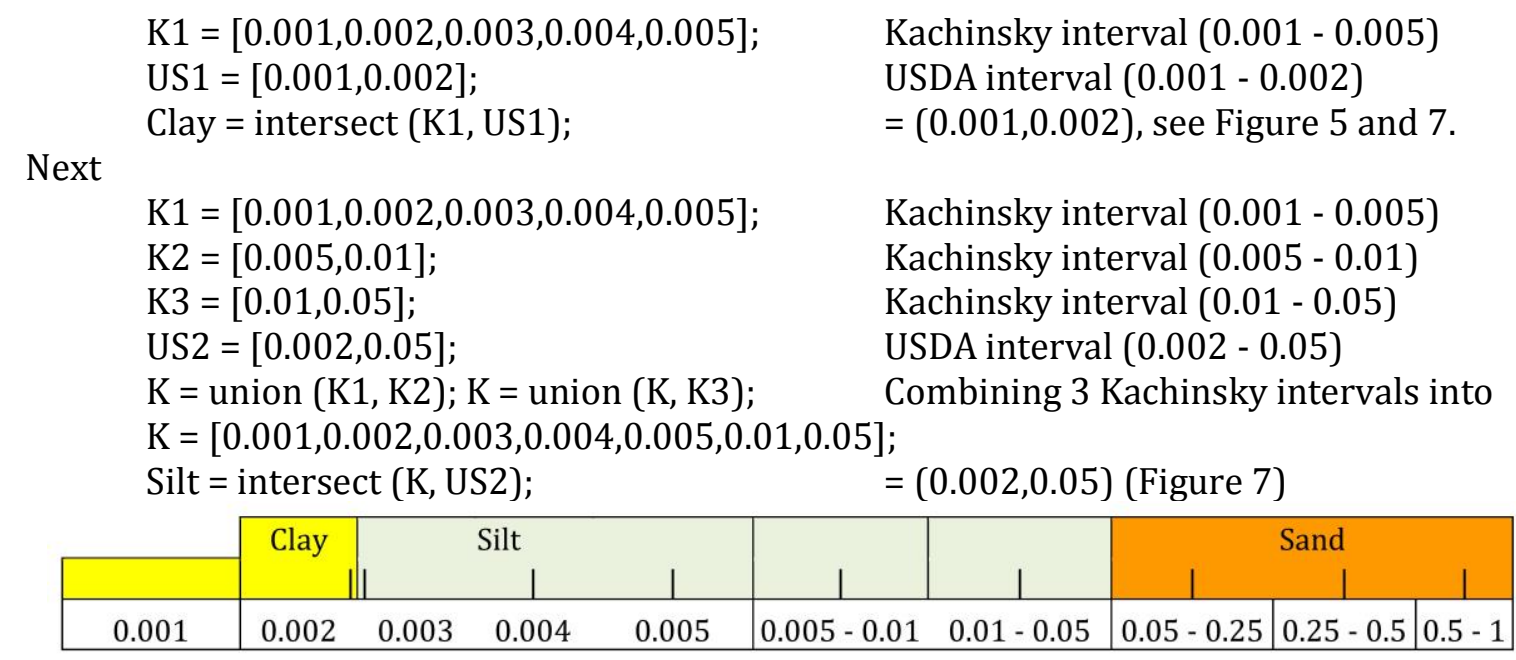

Figure 7. Splitting interval K1 in proportion 1:3 and combining with K2 and K3 intervals.

Here we have formulas for conversion from Kachinsky to the USDA system, which are used in our analysis:

Clay $=(<0.001)+1 / 4(0.001-0.005)$;

Silt = 3/4(0.001-0.005) + (0.005-0.01) + (0.01-0.05);

Sand $=(0.05-0.25)+(0.25-1.0)+(>1.0)$

Gravel $=100-(<0.001)+(0.001-0.005)+(0.005-0.01)+(0.01-0.05)+(0.05-0.25)+(0.25-1.0)+(>1.0)$. 
Continuous pedo-transfer functions (PTF) consisted of multiple linear regression models predicting soil moisture content are using several combinations of independent soil variables (Dobarco et al., 2019). The choice of the soil variables used as arguments for continuous PTFs was based on their correlations with soil moisture content and the evaluation of multicollinearity among variables. The independent variables clay content, sand content, soil organic carbon, and bulk density were chosen to elaborate the PTFs for all horizons.

The disadvantage of this approach is that it does not include the silt content but includes the bulk density, which is one of the dependent variables to be regressed. Also, several regression procedures (stepwise regression, etc.) are known based on the consistent use of some criterion for the significance of the regression coefficients. These procedures are dangerous and can lead to meaningless results, since the latter depends on the pre-selected level of significance, the actual order in which the variables are included or excluded from the model and no biological constraints on the variables are taken into account. For these reasons, the generation of different models is done by reverse elimination, starting with the model containing all possible members for a given class of models and rejecting the members one by one in succession. The selection procedure ends when the external criterion the corrected coefficient of multiple determination reaches its maximum value (Sadovski, 1998). This is equivalent to the condition that all regression coefficients have values greater than their errors, i.e. the criterion $t>1$.

The relationship between the dependent variables $Y$ field capacity, wilting point and bulk density, and independent variables soil sand, silt, and clay content was sought in the form of the following regression equation:

$$
\mathrm{Y}=\mathrm{b} 0+\mathrm{b} 1 \times \text { Sand }+\mathrm{b} 2 \times \text { Silt }+\mathrm{b} 3 \times \text { Clay. }
$$

Applying this selection procedure, it turns out that the constant term of the equation is zero (b0 = 0), and thus we obtain the following results from the regression analysis for the Bulgarian soils, for Plovdiv district and the Canadian soils.

a) Regression equations for Bulgarian soils:

$\mathrm{FC}=0.2718 \times$ Sand $+0.2497 \times$ Silt $+1.2323 \times$ Clay, $\quad$ Adjusted $\mathrm{R}^{2}=0.755$.

$F(3,335)=347.74$, Std. Err. of estimate: 33.436 .

$\mathrm{WP}=0.0190 \times$ Sand $+0.0253 \times$ Silt $+0.3922 \times$ Clay, Adjusted $\mathrm{R}^{2}=0.928$.

$F(3,286)=1236.1$, Std. Err. of estimate: 4.4356 .

$\mathrm{BD}=0.0172 \times$ Sand $+0.0133 \times$ Silt $+0.0138 \times$ Clay, $\quad$ Adjusted $\mathrm{R}^{2}=0.986$.

$F(3,335)=7867.5$, Std. Err. of estimate: 0.16677 .

b) Regression equations for Plovdiv district:

$\mathrm{FC}=0.2992 \times$ Sand $+0.2869 \times$ Silt $+0.4527 \times$ Clay, $\quad$ Adjusted $\mathrm{R}^{2}=0.997$.

$F(3,264308)=3083 E+4$, Std. Err. of estimate: 1.7675 .

$\mathrm{WP}=0.0747 \times$ Sand $+0.0922 \times$ Silt $+0.3765 \times$ Clay, Adjusted $\mathrm{R}^{2}=0.928$.

$F(3,264308)=7911 \mathrm{E}+3$, Std. Err. of estimate: 1.6157 .

$\mathrm{BD}=0.0033 \times$ Sand $+0.0150 \times$ Silt $+0.0241 \times$ Clay, $\quad$ Adjusted $\mathrm{R}^{2}=0.986$.

$F(3,264308)=9150 E+3$, Std. Err. of estimate: 0.12718 .

c) Regression equations for Canadian soils:

$\mathrm{FC}=0.0756 \times$ Sand $+0.3336 \times$ Silt $+0.5749 \times$ Clay, $\quad$ Adjusted $R^{2}=0.965$.

$F(3,54271)=5013 E+2$, Std. Err. of estimate: 5.4926 .

$\mathrm{WP}=0.0281 \times$ Sand $+0.1304 \times$ Silt $+0.3958 \times$ Clay, Adjusted $\mathrm{R}^{2}=0.942$.

$F(3,54271)=2918 E+2$, Std. Err. of estimate: 3.9137 .

$\mathrm{BD}=0.0154 \times$ Sand $+0.0127 \times$ Silt $+0.0137 \times$ Clay, Adjusted $\mathrm{R}^{2}=0.986$.

$F(3,54271)=1243 E+3$, Std. Err. of estimate: 0.1705 .

Remark: Determinations of the three textural classes do not give a sum of $100 \%$, so they may be considered as almost independent variables.

The results obtained show a well-expressed close dependence between the soil texture and its waterphysical properties. It is natural to expect that the corresponding coefficients in the regression equations for the individual water-physical properties will be different for different territories and countries. This difference can be explained by the different conditions in the formation of the soil cover and should be related to the local climatic conditions, respectively to the ecological zoning under the Köppen-Geiger system. 


\section{Conclusion}

The method of discrete mathematics is applied to make the conversion of particle-size classes from the Kachinsky system, which is used in Bulgaria to the International systems. Corresponding conversion formulas have been found to convert Bulgarian intervals of particle distribution to USDA and ISSS particlesize system. On the data basis of 376 soil profiles from Bulgaria, extraction from the SoilGrids system for the Plovdiv district in Bulgaria and data from CanSIS/NSDB database determinations of soil texture and waterphysical properties (field capacity, wilting point, and bulk density) are analyzed. Having such a large amount of data is a prerequisite for drawing reliable conclusions about the relationships between them. The established regression equations have a high coefficient of determination which means they can, therefore, be used to determine water-physical properties of soils from soil texture. The coefficients of regression equations for different territories will differ. This is easily explained by their difference in their ecological zoning. A future study of the relationship between the soil texture and the classes of Köppen for different territories is envisaged.

\section{References}

Abdelbaki, A.M., 2018. Evaluation of pedotransfer functions for predicting soil bulk density for U.S. soils. Ain Shams Engineering Journal 9(4): 1611-1619.

Ahuja, L.R., Naney, J.W., Williams, R.D., 1985. Estimating soil water characteristics from simpler properties or limited data. Soil Science Society of America Journal 49(5), 1100-1105.

Antipov Karataev, I.N., 1960. Soils in Bulgaria. Zemizdat, Sofia, Bulgaria. [in Bulgarian]

Arya, L.M., Paris J.F., 1981. A physicoempirical model to predict the soil moisture characteristic from particle-size distribution and bulk density data. Soil Science Society of America Journal 45(6): 1023-1030.

Børgesen, C.D., Iversen, B.V., Jacobsen, O.H., Schaap, M.G., 2008. Pedotransfer functions estimating soil hydraulic properties using different soil parameters. Hydrological Processes 22(11): 1630-1639.

Dilkova R., 2014. Structure, physical properties and aeration of Bulgarian Soils. Publish SciSet-Eco, Sofia. Bulgaria. 351p. [in Bulgarian]

Dimitrov, E., Kercheva, M., 2016. Assessment of spatial variation and mapping of soil organic carbon and hydrological indices of heterogeneous soil mechanical composition. In: Proc. 4th Nat. Conf. "Humic Substances and Their Role for Climate Change Mitigation", Filcheva, E. et al. (Eds.) Sofia. pp. 142-156. [in Bulgarian]

Dobarco, M.R., Cousin, I., Le Bas, C., Martin, M.P., 2019. Pedotransfer functions for predicting available water capacity in French soils, their applicability domain and associated uncertainty. Geoderma 336: 81-95.

FAO. 2006. Guidelines for soil description, Fourth edition. Food and Agriculture Organization of the United Nations (FAO), Rome. Italy. 97p. Available at [access date : 28.02.2020]: http://www.fao.org/3/a-a0541e.pdf

Fredlund M.D., Fredlund, D.G., Wilson. G.W., 1997. Prediction of the Soil-Water Characteristic Curve from Grain-Size Distribution and Volume-Mass Properties. 3 $3^{\text {rd }}$ Brazilian Symposium on Unsaturated Soils, April 22-25. 1997.Rio de Janeiro, Brazil.

Hengl, T., de Jesus, J.M., Heuvelink, G.B.M., Gonzalez, M.R., Kilibarda, M., Blagotić, A., Shangguan, W., Wright, M.N., Geng, X., Bauer-Marschallinger, B., Antonio Guevara, M.A., Vargas, R., MacMillan, R.A., Batjes, N.H., Leenaars, J.G.B., Ribeiro, E., Wheeler, I., Mantel, S., Kempen, B., 2017. SoilGrids250m: Global gridded soil information based on machine learning. PLoS ONE 12(2): e0169748.

Kachinsky, N.A., 1943. Methods of mechanical and microagregatic analysis of soil. Publ. House Acad. Sci. USSR, Moscow, 39 p. [in Russian]

Kachinsky, N.A. ,1965. Soil Physics. Publ. Higher School, Moscow, 320 p. [in Russian]

Kachinski, N.A., 1956. Die mechanische Bodenanalyse und die Klassifikation der Böden nach ihrer mechanischen Zusammensetzung. Rapports au Sixiéme Congrés de la Science du Sol. Paris, B, pp.321-327.

Kolev, B., Rousseva, S., Dimitrov, D., 1996. Derivation of soil water capacity parameters from standard soil texture information for Bulgarian soils. Ecological Modelling 84(1-3): 315-319.

MacDonald, K.B., Valentine, K.W.G., 1992. CanSIS/NSDB: A general description. Centre for Land and Biological Resources Research. Research Branch, Agriculture Canada, Ottawa. CLBRR Contribution Number 92-35, 40p.

Manrique L.A., Jones, C.A., Dyke, P.T., 1991. Predicting soil water retention characteristics from soil physical and chemical properties, Communications in Soil Science and Plant Analysis 22(17-18): 1847-1860.

Minasny, B., McBratney, A.B., 2001. The Australian soil texture boomerang: a comparison of the Australian and USDA/FAO soil particle-size classification systems. Australian Journal of Soil Research 39(6): 1443-1451.

Nourbakhsh F., Afyuni, M., Abbaspour, K.C., Schulin, R., 2004. Research note: Estimation of field capacity and wilting point from basic soil physical and chemical properties, Arid Land Research and Management 19(1): 81-85.

Pachepsky, Y., Rawls, W. J., 2004. Development of Pedotransfer Functions in Soil Hydrology. Amsterdam: Elsevier, 542p.

Robinson, G.W., 1927. The grouping of fractions in the mechanical analysis. First International Congress of Soil Science. June 13-22, 1927. Washington D.C., USA.

Rodríguez-Lado, L., Rial, M., Taboada, T., Cortizas, A.M., 2015. A pedotransfer function to map soil bulk density from limited data. Procedia Environmental Sciences 27: 45 - 48.

Rosen, K.H., 2012. Discrete mathematics and its applications. McGraw-Hill Higher Education 1071p. 
Rousseva, S.S., 1997. Data transformations between soil texture schemes. European Journal of Soil Science 48(4): 749758.

Sadovski, A., 1998. Self-organizing Models of Biological and Environmental Systems. Journal of Balkan Ecology 1(2): 1520.

Saxton, K.E., Rawls, W.J., 2006. Soil Water characteristic estimates by texture and organic matter for hydrologic solutions. Soil Science Society of America Journal 70(5): 1569-1578.

Saxton, K.E., Rawls, W.J., Romberger, J.S., Papendick, R.I., 1986. Estimating generalized soil-water characteristics from texture. Soil Science Society of America Journal 50(4): 1031-1036.

Shein, E.V., 2009. The particle-size distribution in soils: Problems of the methods of study, interpretation of the results, and classification. Eurasian Soil Science 42(3): 284-291.

Shein, E.V., Kukharuk, N.S., Panina, S.S., 2014. Soil water retention curve: Experimental and pedotransfer data to forecast water movement in soils. Biogeosystem Technique 1(1): 89-96.

Soil Survey Staff. 2017. Soil survey manual. United States Department of Agriculture (USDA) Agriculture Handbook No. 18. Government Printing Office, Washington, D.C., USA. 639p. Available at [access date : 28.02.2020]: https://www.nrcs.usda.gov/wps/PA_NRCSConsumption/download?cid=nrcseprd1333016\&ext=pdf

Sokolovsky, A.N., Kachinsky, N.A., 1930. Soil physics. Second International Congress of Soil Science. July 20-31, 1930. Leningrad-Moscow, USSR.

Teoharov, M., Popandova, Sv., Kancheva, R., Atanasova, T., Tsolova, V., Banov, M., Ivanov, P., Filcheva, E., Ilieva, R., 2009. Reference database for soils in Bulgaria. N.Poushkarov Institute of Soil Science, Sofia. Bulgaria. Publ. House "Poni". Bulgaria. 416p. [in Bulgarian]

Van Genuchten, M.T., 1980. A closed-form equation for predicting the hydraulic conductivity of unsaturated soils. Soil Science Society of America Journal 44(5): 892-898.

Van Genuchten, M.T., Nielsen, D.R. 1985. On describing and predicting the hydraulic properties of unsaturated soils. Annales Geophysicae 3(5): 615-628

Van Keulen, H., Wolf, J., 1986. Modeling of agricultural production: weather, soils and crops. Pudoc, Wageningen, the Netherlands. 479p.

Vereecken, H., Maes, J., Feyen, J., Darius, P., 1989. Estimating the soil moisture retention characteristic from texture, bulk density and carbon content. Soil Science 148(6): 389-403. 